\title{
North Staffordshire Medical Institute: J. T. Arlidge Section of Occupational Health*
}

\author{
A. MEIKLEJOHN, $\dagger$ M.D.
}

Brit.med.f., 1966, 2, 1648-1649

The development by the North Staffordshire Medical Institute of a section of occupational health in conjunction with those on psychiatry and general practice indicates real progress towards its aim to become a medical centre of national importance. It is most felicitous that the section should bear the name of John Thomas Arlidge.

Dr. Arlidge was appointed consultant physician to the North Staffordshire Infirmary in 1862 , and right from the outset he became deeply interested in the occupational aspects of disease and the welfare of the workers and the community. He became the certifying surgeon for Stoke, Longton, and Fenton, and in 1868 became the first president of the Association of Certifying Medical Officers of Great Britain and Ireland (now the Association of Certifying Factory Surgeons). The peak of his contributions to industrial health was achieved in 1889, when he delivered the Milroy lectures at the Royal College of Physicians of London on Occupations and Trades in Relation to Public Health (Arlidge, 1889). On the invitation of Sir Andrew Clark, President of the College, the lectures were extended into a book (Arlidge, 1892).

As a major aim of the J. T. Arlidge section is to promote teaching, training, and practice of occupational health throughout all branches of the profession, it is of interest to note that in the Milroy lectures of 1914 Dr. Frank Shufflebotham, an assistant physician to the North Staffordshire Royal Infirmary, commented:"It seems strange that industrial diseases should have been neglected in the medical schools of this country and by the vast majority of the leaders of the profession, and that the researches in this branch of medical science have been left to individual effort. There are thousands of medical men working in the industrial districts of England who have never received any training in the medical schools on the diseases which they may be called upon at a moment's notice to diagnose and to treat."

\section{Section of Occupational Health}

In recent years the term "occupational" has supplanted industrial, thus emphasizing that the problem is not restricted to manual workers in factories but embraces all forms of employment and all persons engaged therein. Concurrently health has replaced medicine, signifying that the purpose is the prevention of disease by control of the plant, materials, processes, environment, selection, and placement, and supervision and personal protection of workmen at their places of employment. But prevention of disease and maintenance of health are not sufficient ; endeavour must be made, so far as is possible, to make work promote health. This is precisely pronounced in Martial's (A.D. 40-104) epigram: Non est vivere, sed valere, vita-Life is not just living, but living robustly, indeed enjoying it.

However, no matter how efficient preventive measures may be they are never absolute, and new risks arise, so that doctors

* From the Inaugural Address delivered on 26 October 1966. in all branches of practice are confronted with casualties, involving the doctors in diagnosis, treatment, management, and restoration of the patients to work. This means that in teaching, training, and practice the need is to retain both occupational health and occupational medicine.

Review of the incidence of occupational diseases over the past 50 years reveals that considerable progress has been made in the control of the classical ones-lead, mercury, and phosphorus poisoning. However, new hazards have arisen such as atomic radiation, organic chemicals as fertilizers and pesticides, and accidents in demolition of buildings and mechanical harvesting. Furthermore, it has been observed in recent years that mental illness associated with employment has been on the increase. The important fact, however, is that occupational ailmentsaccidents and diseases-account for only $10 \%$ of all spells of sickness among employed persons. This indicates the major incidence of social diseases and the adverse influences of community environment and social habits. The significance of this is that in the case of the worker the approach must not be narrow and confined to his employment but should be comprehensive of the whole man in his total environment. The connotation of the total environment has been clearly outlined by Industrial Medicine and Surgery (1962): "In addition to his work environment the industrial worker possesses a home environment, a nutritional environment, a recreational environment, seasonal environment, among many others. The sum becomes the total environment, part hostile, part friendly."

There is the further point that we live in an ever-changing world, and this means that we must unremittingly be alert and progressive in our approach and attack.

In the investigation of individual cases, as originally pronounced by Ramazzini, the occupational history is fundamental, and this involves not merely the name of the trade, as is so common in hospital records, but factual information about the raw materials, processes, details of similar affections among fellow workers, and environmental and personal protective measures. Comprehension of the history can be achieved only by regular organized visits to local industries. Managements, it will be found, welcome such interest and provide full facilities.

\section{Infection from Abroad}

At present large numbers of immigrants from all over the world are employed in British industry, and air transport enables members of management teams and others to make trips abroad.

Accordingly the occupational history should be supplemented by inquiry, as outlined by Professor B. Maegraith (1963) in "Unde Venis?: Where have you been and when were you there ?" The reason is that some of these persons may be carriers of tropical diseases due to micro-organisms or parasites. It is remarkable that Shufflebotham (1914) stated: "I believe that the law should provide for a compulsory medical examina- 
tion of all applicants for work in coal mines who have been in the tropics or in the colonies or who have worked in European mines or even in the tin mines of Cornwall where ankylostomiasis [hookworm disease] may prevail. It is only from such sources that the coal mines of this country can be infected, and every means should be taken to prevent any infection ever occurring."

In 1964 Salem and Truelove recorded the discovery of hookworm disease in Pakistani immigrants resident in Oxford. Ankylostomiasis became epidemic in the Belgian coal mines in 1965. Cognate to this matter is that in the pre-employment medical examination in this country it is usual to include radiographic examination of the chest. In Egypt greater importance is attached to $x$-ray examination of the pelvis because of the serious effects of the complications-calcification and cancer of the bladder - of chronic bilharziasis, which affects over $60 \%$ of the adult population.

In all its activities the section must maintain close cooperation with the University of Keele, the North Staffordshire Royal Infirmary, the North Staffordshire Technical College, the British Ceramic Research Association, and local professional and trade organizations. Interest as a group and individually should be taken in relevant national and international bodies.

Josiah Wedgwood-the great potter-was elected F.R.S. for his studies in pyrometry, and in his writings he stated: "Everything yields to experiment." Possible early studies for the section are occupational health services for hospital staffs and the anatomy of contentment in industry. Just as Lord Moran's anatomy of courage involved detailed dissection of fear so anatomy of contentment involves dissection of discontent. Another possible project is presented by the effects of ageing on working capacity and craftsmanship in local industries with a view to provision of timely adjustments and preparation for retirement.

\section{A Daily Reminder}

Finally, in the centre of the Potteries in Hanley the whole populace of North Staffordshire has a daily reminder of the care and the well-being of all workers; this is Piccadilly. It is in Piccadilly Circus, London, that Eros, the God of Love, stands on the Shaftesbury Memorial, erected in 1893 by public subscription to Anthony Cooper, K.G., Seventh Earl of Shaftesbury.

This symbolizes the love of a great Englishman for the factory and mine workers of this country. According to the inscription composed by the then Prime Minister, the Right Honourable William Ewart Gladstone:

During his Public Life of Half a Century

He Devoted the Influence of his Station

The Strong Sympathies of his Heart

And the Great Powers of his Mind

To Honouring God by Serving his Fellow Men.

An example to His Order, a Blessing to his People

And a Name to Be by Them

Ever Gratefully Remembered.

This section of occupational health is born with a great heritage. Under the distinguished president of the institute, the chairman, committee, and members of the occupational health section will, I am convinced, accept and follow the inspiration embraced in this Shaftesbury inscription and in the work of their titular leader, John Thomas Arlidge. Thereby they will render dedicated service not only to the local populace but to all mankind.

\section{REFERENCES}

Arlidge, J. T. (1889). Brit. med. 7., 1, 580, 642, 702, 766. (1892). The Hygiene and Diseases and Mortality of Occupations.

Industr. Med. Surg., 1962, 31, 513.

Maegraith, B. (1963). Lancet, 1, 401.

Salem, S. N., and Truelove, S. C. (1964). Brit. med. 7., 1, 1074.

Shufflebotham, F. (1914). Ibid., i, 755 .

\section{Medical Termination of Pregnancy Bill ${ }^{*}$}

\section{Views of the British Medical Association and the Royal College of Obstetricians and Gynaecologists}

The following document was approved by the Council of the B.M.A. at its meeting on 21 December.

\section{Safeguards}

Clause 1(1) permits any registered medical practitioner to terminate a pregnancy. This is not sufficient and we recommend that it be made obligatory for the termination to be carried out by, or under the supervision of, a consultant in the National Health Service, or such other doctor of equivalent status and experience as the Minister shall approve for the purpose of the Act.

Both the B.M.A. and the R.C.O.G. agree that the consultant should be a consultant in gynaecology and the R.C.O.G. would like this written into the Act. The B.M.A., however, feels it would be preferable not to exclude other consultants-for example, a consultant surgeon-as this would preclude the operation being carried out in certain parts of the country where a consultant gynaecologist is not readily available.

On many occasions it will be necessary for more than two doctors to agree before termination is carried out. We would like the requirement to be that the opinions of "at least" two medical practitioners are obtained.

Clause 1(2) permits termination to be carried out in any registered nursing-home. The reference to a registered nursinghome should be deleted so that the operation has to be carried

* Text of Mr. Steel's Bill is reproduced at p. 1650. out in a National Health hospital or other place approved for the purpose by the Minister.

\section{Indications}

Provided the above safeguards are incorporated it is both unnecessary and undesirable to frame the indications for termination too narrowly. The requirements that the risk has to be serious and the injury to health grave in clause $1(1)(a)$ are capable of causing considerable difficulties in practice and may mean that terminations carried out on certain medical indications which are accepted under current medical practice would become questionable in future.

The indications should be framed " in the interests of the health of the mother or because of the (substantial) risk of serious abnormality of the foetus." Although the B.M.A. and the R.C.O.G. are in agreement that the risk of serious abnormality to the foetus must be " substantial," the B.M.A. has reservations about this qualification being included in the Act, bearing in mind the difficulties which have occurred in previous statutes when "substantial" has been used as qualifying medical opinion-for example, substantial mental impairment in the Homicide Act. (See also Lord Dilhorne's comments in the debate on Lord Silkin's Bill, Hansard, 28 February 1966, col. 528.)

Clauses $1(c)$ and $(d)$ are objectionable in specifying indications which are not medical. They will, in our opinion, give rise to serious difficulties in practice. They might well lead to 